\title{
Elderly People in Many Respects Benefit from Interaction WITH DOGS
}

\author{
R. Scheibeck, M. Pallauf, C. Stellwag, B. Seeberger \\ UMIT - Private University of Health Sciences, Medical Informatics and Technology, \\ Institute of Gerontology and Demographic Development, Hall/Tirol, Austria
}

\begin{abstract}
Over the course of evolution, humans and animals have entered into a close relationship. By domesticating animals, humans were able to use them to their own advantage. However, animals should not only be seen as mere providers of material value; in fact, they actually enrich humans' lives on an emotional level. The classic examples for this evolution are dogs: they are considered loyal companions, particularly for children and elderly people. This relationship between humans and animals is the subject of this research study and is examined from a gerontological perspective by employing qualitative social research methods. Conclusion: The results of the study reveal the manifold meanings that pets - in particular dogs - can and do have to the elderly. At this point, it should also be noted that there is still a strong need for further research into this topic from a gerontological perspective.

Key words: dogs and the elderly, human-dog relationship, pets and the elderly, pets as social facilitators, solitude
\end{abstract}

\section{BACKGROUND}

Humans have longed for love and attention since the dawn of their existence,. As socially-active and socially-minded beings, humans need interpersonal contact, be it with only one person or a whole group. If they do not manage to establish these contacts, negative consequences may arise that will ultimately push them to the brink of extinction. Humans do not naturally look for superficial bonds, but rather appreciate deep relationships that might eventually give rise to friendships. However, this requires building confidence, which can be a rather time-intensive process. Many elderly people simply are not able to establish new social contacts and the subsequent strong bonds when trying to compensate for the loss of their partners or the transition to retirement (Ludwig 2001). However, they long for an intimate and loving companionship. A pet can be such a companion. In most cases, pets can satisfy both the longing for company and the desire for affection.

Also older adults owning a pet were more likely to engage in physical activity than non-dog or non-pet owners. This was investigated and it was found out that dog owners engaged in greater overall physical activity (Thorpe et al. 2006).
To some people, a pet is 'just' an animal. However, to a pet lover a pet is a friend, true partner, and loyal companion. All too frequently the companionship of a pet is underestimated or belittled, even though pets are often intimate companions for many elderly people. They help them fight off loneliness and solitude and continue their activity. To many elderly people, their animal friend means joy and quality of life (Otterstedt and Rosenberger 2009). As a consequence, relationships between humans and animals should always be respected and never underestimated. Dogs as domestic animals are of particular importance to many of the elderly, even if the extent of this relationship is determined by a variety of influences, emotions, and experiences. This study aims to examine this relationship. Preliminary results have been published in Scheibeck et al. 2011.

\section{Research Design: Human-Animal PROJECT}

\subsection{Research Aim and Research Questions}

Dogs are considered mankind's longest-standing animal companions. Throughout the history of humanity, dogs have always played an important role for humans. In more recent times, dogs have become emotional companions and human substitutes for people living in solitude, and they have given new meaning to elderly people's lives. This fact lays the foundation for the aim of this research study: to examine the human-animal relationship - and, in particular, the human-dog relationship - from a gerontological perspective. The study will illustrate the individual meaning that dogs have to their elderly owners and the relationships that form between owners and their four-legged companions.

Therefore, the following research question will guide the study:

How important are dogs to the elderly?

Further questions arise from the research question:

- What is the age structure of dog owners?

- What are the activity patterns of elderly dog owners?

\subsection{Research Area And Research Group}

As the research area, the author of the study selected several larger communities in the Austrian province of 
the Tyrol. The research group was defined as elderly dog keepers. The exact age of the dog owners will play a relevant role only later when dealing with one of the questions arising from the research question.

\subsection{Methodical Approach}

The methodical approach is characterized by explorative methods. This research study is based on qualitative social research. The reason why the author chose to employ qualitative social research is that it takes a more open approach to the examined phenomena and is, therefore, often closer to them than research strategies that rely on big numbers, standardized methods, and normative concepts (Flick 2008). The author chose to use the following elements of qualitative social research:

- systematic literature research,

- data collection according to Grounded Theory,

- ethnographic interview, and

- ethnographic field research.

The author deliberately chose to adopt a quite comprehensive approach in order to examine the research subject from different perspectives and thereby obtain a comprehensive picture. The methods listed above are in chronological order. The methodical aspects of this approach are described in the following sections.

\subsubsection{Systematic literature research}

Systematic literature research (Flick 2007a) was employed as the basis for this research project. It was carried out between March and June 2010 and included the following sources: Gerolit online library catalog of the German Centre for Gerontology (Deutsches Zentrum für Altersfragen, DZA) and the EBSCO database. In addition to these sources, the author researched websites, such as Springerlink, Google Books, and Google Scholar, using the following German-language and English-language keywords:

Table 1. Key words used for the systematic literature research.

\begin{tabular}{ll}
\hline Tiere und ältere Menschen & animals and the elderly \\
Mensch-Tier-Beziehung & human-animal relationship \\
Haustiere und ältere Menschen & pets and the elderly \\
Senioren und Haustiere & seniors and pets \\
\hline
\end{tabular}

2.3.2 Data collection according to Grounded Theory In order to identify the age structure of dog owners in the Tyrol, the author used secondary data collection (Pepels 2008), directly addressing the relevant statistics offices. The aim was to determine the age of dog owners at the time of the dog's first registration. Several larger Tyrolean communities were included in this process of data collection.

For the collection of data, the author used theoretical sampling, which is an element of Grounded Theory. According to Corbin and Strauss, theoretical sampling "means the generation of theories from data in the process of conducting research. During this process, the researcher collects data in parallel, codes and analyzes them and decides which data are to be collected next and where to find them. This process of data collection is determined by the nascent - material or formal - theory." (Strübing 2008).

\subsubsection{Ethnographic interview}

The research question implies interviewing participants at their places of residence or, to be precise, their and their dogs' places of living. Therefore, this procedure can be described as an ethnographic method. To conduct the interviews, the author chose to use ethnographic interviews following semi-structured guidelines.

Basically, ethnographic research follows a structure that is subject to certain dimensions:

- Examination of a spatially and temporally limited unit of analysis (e.g. person, group, or institution),

- that documents the collected data and the subsequent findings

- found by a single researcher, a pair or a team of researchers

- during a certain period of time in which the researchers participate in the subject's daily life while observing and interviewing them and collecting data (Friebertshäuser 2007).

In order to give an even clearer picture of the distinctive features of ethnographic research, the following methods of ethnographic research should be mentioned. On the one hand, there is the specific method of participant observation, in which the researcher focuses on observing the subject's everyday behavior and situations. On the other hand, there is cross examination, which refers to the use of more than one method to compensate for the weaknesses of each of the individual methods (Flick 2007b). This mix of methods is used much like triangulation (Flick 2007b). However, the combination of qualitative and quantitative methods and the obligation to use an inductive approach must also be considered. One of the central elements of ethnographic research is the description and analysis of an examined case which can be a single person, a group of people, or social sub-cultures (Friebertshäuser 2007).

\subsubsection{Ethnographic field research}

A further element employed in this study is ethnographic field research. Together with other socio-scientific procedures, ethnographic field research is "a method for the collection of data which fundamentally sets itself apart from other procedures in at least two aspects, due to the fact that methods are not only procedures for collecting data but are also procedures for establishing a connection with the field. This means that methods imply certain forms of interaction with the researched field." (Univie 2010). The focus in ethnographic field research is thus on relationships: "Ethnographic field research is characterized by a particularly intensive, long-term relationship with the examined field, which goes beyond the mere collection of data. This is a key criterion of quality in ethnographic research." (Univie 2010). Therefore, it can be stated that ethnographic research "is not only a procedure aimed at generating data, but, above all, a procedure aimed at generating emotional and factual experiences which gradually turn the field researcher into a 
part of this field." (Univie 2010). Finally, the information gathered will be processed: "A central element in the process of field research is the systematic taking and elaborating of field notes which will transform these experiences into data. In ethnographic field research, the use and the applicability of research strategies and methods are determined to a much greater extent by the field itself than in any other research approach." (Univie 2010).

\section{RESULTS}

The following section will present the results of this research. The findings are arranged systematically, according to the research steps presented in items 2.3.1 to 2.3.4.

\subsection{Results of the Systematic Literature RESEARCH}

The results of the literature research in books can be summarized as follows: the human-animal relationship is a neglected topic that is addressed only marginally. Rheinz describes the interaction between humans and their pets as "terra incognita" (Rheinz 1994). It is unknown terrain that requires further exploration. In her book Eine tierische Liebe (Animal love) (Rheinz 1994), Rheinz describes various types of relationships between humans and animals. Among other issues, she addresses the trauma of separation, the aspect of affection for animals, and the issue of animals as partners. In his book Das Tier und wir (The animal and us), Serpell writes about animals as substitutes for humans, pets as a panacea, and the friendship between humans and animals (Serpell 1990). In their book Tiere und Menschen (Animals and humans) (Münch and Walz 1998), Münch and Walz point to the fact that there are huge research gaps in the examination of this relationship. However, they also state that numerous analyses and syntheses in this field have been developed that have proven to be very valuable. Nevertheless, they see the need for developing further perspectives and integrating the different research approaches (Münch and Walz 1998). According to Balcombe, the number of scientific papers on this issue is on the rise. In particular ethology, a recognized field of research, examines this relationship (Balcombe 2000). Another book worth highlighting in this respect is the guidebook Ein Plädoyer für die Tierhaltung in Alten- und Pflegebeimen (In favor of pet keeping in retirement and nursing homes) by Olbrich and Jonas (Olbricht and Jonas 2008), which focuses on the human-animal relationship. The authors come to the conclusion that, though animals cannot replace interpersonal relationships, they can substantially improve the well-being of elderly people, take pressure off nurses, and facilitate therapy. In Olbrich's view, dogs, cats, and birds are often much more effective in therapy than any medication. Their studies showed that those residents keeping an animal were often much more active, self-conscious, and communicative. The pets kept their owners active and occupied; they made them feel needed, and helped them to establish social contacts; they enlightened their everyday lives; and they distracted them from distressing events. In addition to that, surveys carried out since the 1980s, both at home and abroad, showed that pet owners had a lower risk of falling ill, suffered less from cardio-vascular diseases, were happier overall, and felt unwell less often (Olbrich and Jonas 2008). In their book, Olbrich and Otterstedt recognize that animals bind their owners to life (Olbrich and Otterstedt 2003).

\subsection{Results of the Data Collection}

The planned data collection took place at three statistics offices in the larger communities and cities in the Tyrol in order to find an answer to the following question: What is the age structure of dog owners?

The author's intention was to identify how many elderly, single persons own a dog. The results of this investigation would have provided the author with the basis for her next research step. The author worked with the staff of the different statistics offices on-site to search for the relevant data. However, it turned out that the only data available were the names and addresses of the dog owners. Although every single dog in the various communities was registered, there was no information listed regarding the age of their owners. After visiting the third statistics office, theoretical saturation was reached. This is, according to Glaser and Strauss, the criterion "that determines when sampling (per category) can be stopped" (Glaser and Strauss 1998). After the visit at the third statistics office, the data collection process ended and the author continued with the next step in the methodical approach. As a result, the question raised above cannot be answered.

\subsection{ETHNOGRAPHIC INTERVIEW}

The author interviewed a total of 23 elderly, single persons $(n=23)$ above 70 years of age in their homes; there were 5 male and 18 female respondents. The interview respondents were chosen according to the principle of random selection (Brüsemeister 2008). After the $23^{\text {rd }}$ interview, theoretical saturation according to Glaser and Strauss was achieved. Theoretical saturation is a criterion "that determines when sampling (per category) can be stopped" (Glaser and Strauss 1998). The interviews were based on the following question:

What are the activity patterns of elderly dog owners in the Tyrol?

This question provided the basis for the following interview questions:

How often and for how long do you usually take your dog for a walk (self-evaluation)?

- Most of the respondents indicated that they take their dogs for a walk three times a day. Results show that there is a difference between respondents who have a backyard (defined as individuals owning a fairly large property) and respondents without a backyard. Elderly dog owners with a backyard spend an average of 100 minutes per day walking their dogs, whereas elderly dog owners without a backyard spend an average of 140 minutes. 


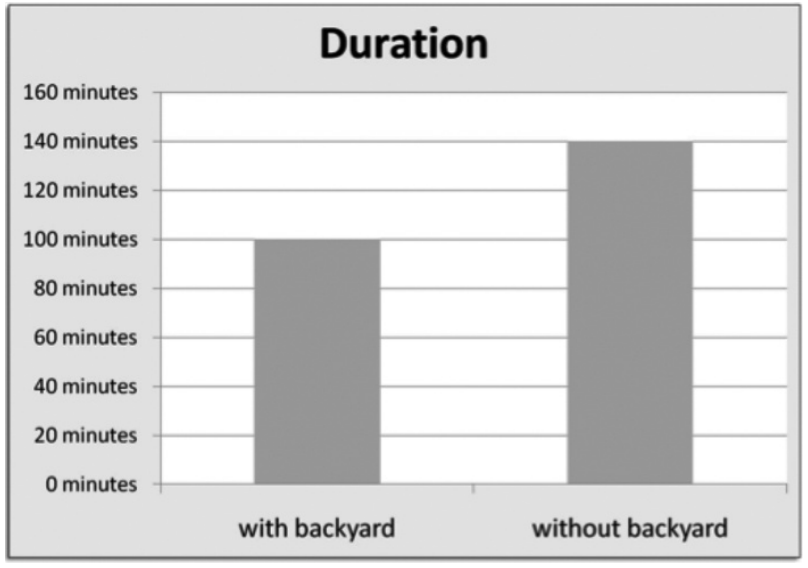

Fig. 1. Daily duration spent for walking the $\operatorname{dog}$ (dog owners with and without backyard).

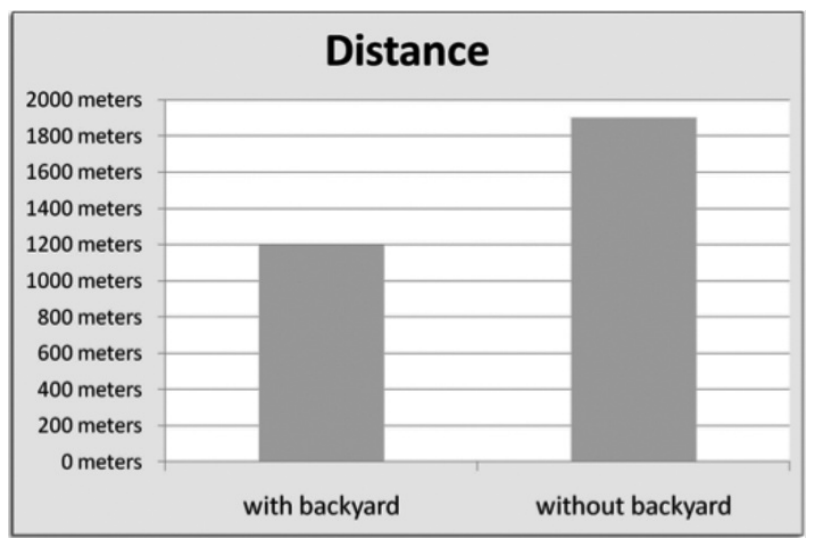

Fig. 2. Daily distance covered by walking the dog (dog owners with and without backyard). This implies that backyard owners often let their dogs run around in the backyard instead of taking them for a walk.

What distance do you walk on a daily basis (selfevaluation)?

- The same difference becomes evident here: respondents who have a backyard covered an average of 1,200 meters (approximately 0.75 miles) per day; subjects without a backyard covered an average of 1,900 meters (approximately 1.18 miles) per day.

A further research question was:

How important are dogs to their owners?

This question gave rise to the following interview question:

How important is your dog to you in your current life situation?

Listed below are some typical examples of answers given by respondents:

- "My dog notices if I'm doing well or not. I talk to him; there is always someone in the apartment, and I'm not alone. "

- "He watches over me; he gives me a purpose."

- "I have to go outside with him and exercise: this is also good for me."

- "When I'm outside with my dog, I always meet new people and chat with them."

- "My dog means everything to me - even more than my relatives do."
- "I wouldn't want to be without my dog!"

These typical examples show that dogs are important to their owners and enrich their lives.

The results of these interviews can be summarized as follows:

- Dogs can be partners in life and companions in an apartment.

- Dogs give their owners a purpose (feeding, care) and a daily structure (going outside three to four times a day).

- Owners associate their dogs with memories of deceased family members or children who have moved away.

- Dogs can be social facilitators.

\subsection{Ethnographic Field Research}

Since the collection of data on the age of dog owners did not lead to any significant results, the author decided to include a further aspect in the research project and, therefore, developed an additional research step: ethnographic field research through observation and structured small-talk conversations carried out in dog cemeteries in Munich, Salzburg, and Vienna.

The obtained results are described below according to the respective methods used:

\section{Additional method: field observation}

The dog cemeteries of the three cities are all located outside of the city: one in a recreational area at the outskirts of a forest, one in the proximity of a community garden, and one close to a farm that had provided the property for the cemetery. Like normal cemeteries, dog cemeteries have rules and regulations as well as opening hours. The various dog graves are framed with wooden decorations or stones and have small gravestones indicating the name and often the dates of birth and death of the dog. Many graves are decorated with flowers; often, the mourning has placed a dog toy next to the grave, which had probably been the dog's favorite toy. The majority of graves remain in existence ten years or longer.

The visitors take care of the graves, water the flowers, or clean the small gravestones. Most of the visitors spend between 20 and 30 minutes in the cemetery. Some visitors greet others and make small talk. Two married couples make plans to go to a café near the cemetery once they are finished. Many visitors have a picture of their deceased dogs in their wallets. The author also observed that the majority of visitors adopt a devotional posture when arriving at the grave. Only afterwards do they approach other visitors or start to clean and decorate the graves. The floral ornaments used to decorate the dog graves are no different from those used for human graves.

\section{Structured small-talk conversations}

The author led a total of 16 small-talk conversations in the three cemeteries. The conversations took place from September to November 2010. The various conversations lasted between 10 and 65 minutes and were each transcribed from memory by the author. Bringing her own dog made it significantly easier for the author to enter into contact with the cemetery visitors. The 
respondents included 16 persons between 61 and 76 years of age, as shown in the following Table.

Table 1. Age groups of the respondents.

\begin{tabular}{ccc}
\hline Age group & \multicolumn{2}{c}{ female $^{\text {thereof }}$} \\
& male \\
\hline $60-65$ & 2 & 1 \\
$65-70$ & 4 & 2 \\
$70+$ & 5 & 2 \\
\hline
\end{tabular}

All conversation partners had lost their dog in the preceding two to five years. All of them spoke about strong emotional and empathetic experiences that they had with their dogs. Respondents indicated that, on average, they visited the cemetery between two and four times per week. Listed below are some typical examples of answers given when asked about the importance of visiting the dog's grave:

- "We feel close to our dog, who accompanied us for a long time and knew us very well and whom we knew very well, too".

- "Our dog remains a big memory in our lives that we wouldn't want to be without."

- "The dog was all but our child, and that is why we have given him this grave."

- "I always meet people here who also used to have a dog, like me, so you can talk to them about it."

- "We are like a community where everyone knows each other and everyone understands what it means to be here; we don't need to explicitly talk about it."

Some interesting typical answers were given in response to the question on the meaning of the dog to its owner while it was still alive:

- "We were two peas in a pod."

- "My poodle always understood me, and when my husband passed away he was as sad as I was."

- "You know, we never had children and we have had several dogs before. However, this one had been with us for almost 20 years, and accompanied us through very difficult times; he had become a part of our little family."

- "He wasn't a dog to me. When I ate, he sat at the table with me; when I was sick he instantly noticed it and became extremely nervous."

- "Well, to us, our dog was a substitute for the children we never had, and we were never ashamed of that. We probably saw more in him than just a dog, but that's just the way it was."

A further question aimed at finding out about how respondents coped with the dog's death and how they got over it. Again, some representative answers are given below:

- "Yes, of course I was very sad, but we didn't get a new dog. We didn't want a new dog because we didn't want to blur the memories and the experiences we had with our deceased dog."

- "Yes, I was indeed sad; just as sad as if a real person had passed away. It took me a long time to get over it and, in the beginning, I came here almost daily. No, I never wanted to get a new dog after that."

- "When my dog died, it was as if the time we had spent together had died with him. Even if I have a new dog now, the memory of my dead dog is still alive."

- "I didn't want the dog to suffer; therefore, I had to have him put to sleep. The fact that he lies here gives me great strength and, therefore, I never ended up being sad about it."

\section{Discussion of Results}

Many elderly people suffer from loneliness after they lose their partner or after they retire. They feel a certain lack of purpose that would give sense to their everyday lives. Retirement becomes an ever-increasing burden to them. These new circumstances often also cause them to lose their social contacts. A pet - and, in this case a dog - can serve as a kind of medium through which social contacts can be established in everyday situations. In addition to that, dogs give their days a certain structure; fixed times for meals and walks provide elderly people with the feeling that they have a purpose and a responsibility towards someone. Dogs give a certain meaning to their lives, since the task of caring for a dog also means a great responsibility.

About that subject a study was published in which no conclusive results could be shown how pets have a positive impact on the physical and psychological health of their owner (Chur-Hansen et al. 2010). On a related subject Raina et al. did a longitudinal study in which they were able to prove that keeping a pet has a positive impact on social support and psychological well-being (Raina et al. 1999).

In an increasingly singular society, the psychological importance of the human-animal relationship is growing, particularly for the elderly. Keeping a pet means keeping fit: this anaphora could serve as an interpretation of the results and as a motto for elderly dog owners. It also sounds pretty fitting when considering the findings of this research study. For example, the literature research shows that human-animal relationships are win-win-situations. The results of the ethnographic interviews also illustrate some interesting aspects: they confirm the motto mentioned above, since the interviews show that elderly dog owners walk quite a distance each day, and physical activity is in general very healthy, provided that it does not damage the joints. This was also shown by Yabroff et al. who demonstrate that dog owners show a higher physical activity (Yabroff et al. 2008). In general, dog owners are more active on a daily basis than other people, if only because of the fact that they have to take their dogs for a walk several times a day. Seen from this perspective, city parks can be considered a kind of motivational strategy to encourage dog owners, their canine companions, and others to become active and to meet new people.

Another study examined the association between dog ownership and adult physical activity levels. While there is evidence to suggest that dog ownership produces considerable health benefit and provides an important form of social support that encourages dog owners to walk, there is limited evidence on the physical, environmental and policy-related factors that affect dog owners walking with their dog (Cutt et al. 2007). 
Other studies already examined the extent to which dog owners and non-dog owners differ in their constitution. In Sweden Müllersdorf et al. compared the two groups concerning aspects of health, physical/leisure activities, work and socio-demographics. They found that in all categories which were to be evaluated differences were noted, however, both positively and negatively. Regarding the general state of health there could be detected a better state at the dog owners (Müllersdorf et al. 2009). A review detected that dogs have a number of positive effects on human health and well-being (Larsen and Lingaas 1997).

Another study explored the association between pet ownership and self-reported health in people suffering from chronic fatigue syndrome (CFS). The findings of this study suggest no statistically significant association between pet ownership and self-reported health in people with CFS. Nonetheless, people suffering from this condition believe that their pets have the potential to enhance quality of life (Wells 2009).

In addition to that, statements made during the ethnographic interviews, such as "My dog means everything to me" show the huge importance of pets and the confidence that is placed in them. The absence or insufficiency of emotional or intimate social relationships is projected onto the pet or the dog. The fact that owners treat their pets like human beings implies that owners have a considerable set of expectations. However, this expectation dimension should not be interpreted as being objectivist. Nevertheless, the physical presence and the possibilities of physical contact that are offered by the pet seem to compensate for this meaning.

An important aspect that deserves to be addressed is the grief that grips dog owners after they lose their beloved four-legged friend, as reflected in the results of the ethnographic field research. This kind of grief is comparable to the grief that follows when people lose a dear friend or relative: the same is true for mourning behavior and rituals like cemetery visits. Setting up a grave site means to actively preserve the memory of the dog and any related experiences and emotions. However, the grave site also serves as a constant reminder of the grief and sadness provoked by the death of the beloved companion. Therefore, it may be stated that dog cemeteries as places of commemoration for the elderly are a completely neglected field of research in social or cultural gerontology. At the same time, animal cemeteries show the importance of animals to their owners and the equal value of animals and humans when it comes to grieving and coping with loss. However, the three cemeteries visited by the author also showed, to an alarming extent, that many elderly people do not have any social contacts anymore and that their dogs had been human substitutes to them. This clearly shows that an intensive human-animal relationship is indeed possible, and probably every dog owner would testify to this statement and defend it. However, on the other hand, it is impossible to say if the dog really felt as comfortable in this relationship as its owner. What is clear is that animals - and in this case dogs - are and were substitutes for partners and children; that they helped their owners to distract them and fight off boredom, and that there was a daily responsibility towards the dog. The socio-psychological impact, in particular regarding age, would still need to be framed and generated from future research studies.

Finally, the use of dogs as therapy animals was seen in several studies. These studies revealed many psychological benefits for patients with dementia (Larsen and Lingaas 1997, Perkins et al. 2008, Tribet et al. 2008). Also cardiovascular effects of a human-dog relationship were examined. Studies about this subject showed that dogs have a positive influence concerning for example heart rate and blood pressure (Baun et al. 1984, Allen et al. 2002, Virués-Ortega and Buela-Casal 2006).

\section{Further NeEd for Gerontological RESEARCH}

The present research study tries to give a first structure to the topic of animals and the elderly, a subject that, so far, has not been examined in this way. This paper is, therefore, to be understood as a first gerontological approach to the topic. As a result, further research is needed in the following areas:

An essential aspect that needs further research is the collection of data regarding the age structure and actual age of dog owners in the Tyrol. Therefore, the following possible research questions may be posed:

- What is the age structure of dog owners?

- How many dog owners are over 70 years old?

Moving into a retirement or nursing home can mark a watershed in an elderly person's life. This sometimes involuntary move can often be accompanied by material as well as emotional loss. What happens to the pet if relatives, children, or friends cannot or do not want to take care of it? Additionally, many retirement and nursing homes do not allow pets to be brought to the new "home". Further research would be needed to give answers to the following questions:

- What happens to an elderly person's pet or dog if they move to a retirement or nursing home?

- Which options could retirement or nursing homes offer in order to make it possible for future residents to bring their pets?

Since pets - and again, in particular dogs - have a positive effect on humans (a fact that has been substantiated in many studies and research projects), a further question for research could address the subjects' ages. From a gerontological perspective the focus would, therefore, have to be placed on elderly subjects and their social contacts or social networks:

- How does a pet or a dog influence an elderly person's lifestyle?

- How does a pet or a dog influence the establishment of social contacts by elderly people?

- How does a pet or a dog influence the economic site of a social system with a growing number of elderly people?

In conclusion, further gerontological research needs to be carried out in order to examine the fact that emotions are an essential part in the animal-human relationship. Therefore, the following questions need to be addressed:

- Is there a link between elderly dog owners and depression or medication? 
- How can dogs be used to facilitate elderly people's therapies?

- What influence can a dog have on loneliness and isolation in an elderly person?

\section{Conclusion}

Based on the results the research questions can be answered as follows:

It has been shown that a dog has an important meaning for older people and contributes positively to the lifestyle. The question concerning the age structure of dog owners could not be answered. Older people with dogs are covering an average daily distance of 1,500 meters (approximately 0.95 miles), depending on the garden property.

In addition it can be stated, that the results of the systematic literature review confirm the results of the research conducted by the author. For instance this can be shown on points like the love of man to animals or the animal as a substitute for a partner. The positive impact on the movement and the social contacts of the dog's owners could also be verified.

\section{REFERENCES}

Allen K, Blascovich J, Mendes WB. Cardiovascular reactivity and the presence of pets, friends, and spouses: the truth about cats and dogs. Psychosom Med. 2002 Sep-Oct;64(5): 727-39.

Balcombe J. Tierisch vergnügt. Stuttgart: Franckh- Kosmos, 2000: 10. ISBN 978-3440110065.

Baun MM, Bergstrom N, Langston NF, Thoma L. Physiological effects of human/companion animal bonding. Nurs Res. 1984 May-Jun;33(3):126-9.

Brüsemeister T. Qualitative Forschung. Ein Überblick. Wiesbaden: VS, 2008: 173. ISBN 978-3531162881.

Chur-Hansen A, Stern C, Winefield H. Gaps in the evidence about companion animals and human health: some suggestions for progress. Int J Evid Based Healthc. 2010 Sep;8(3):140-6.

Cutt H, Giles-Corti B, Knuiman M, Burke V. Dog ownership, health and physical activity: a critical review of the literature. Health Place. 2007 Mar;13(1):261-72. Epub 2006 Feb 28.

Flick U. Qualitative Sozialforschung. Eine Einführung. Reinbek: Rowohlt, 2007a: 14, 74. ISBN 978-3499556944.

Flick U. Triangulation. Eine Einführung. Wiesbaden: VS, 2007b: 11, 77. ISBN 978-3531156668.

Flick U. Qualitative Sozialforschung. Ein Handbuch. Reinbek: Rowohlt, 2008: 17. ISBN 978-3499556289.

Friebertshäuser B. Feldforschung und teilnehmende Beobachtung. In: Friebertshäuser B, Prengel A. Handbuch qualitative Forschungsmethoden in der Erziehungswissenschaft. Weinheim: Juventa, 2007: 504. ISBN 9783779907930.

Glaser BG, Strauss AL. Grounded Theory. Strategien qualitativer Forschung. Bern: Huber, 1998: 69. ISBN 9783456828473 .

Larsen BA, Lingaas F. Dogs and health. A review of documented connections. Tidsskr Nor Laegeforen. 1997 Dec 10;117(30):4375-9.

Ludwig C. Wenn das Haustier stirbt. Köln: VGS, 2001. ISBN 978-3802514364.

Müllersdorf M, Granström F, Sahlqvist L, Tillgren P. Aspects of health, physical/leisure activities, work and socio-demographics associated with pet ownership in Sweden.
Scand J Public Health. 2010 Feb;38(1):53-63. Epub 2009 Aug 28.

Münch P, Walz R. Tiere und Menschen. Paderborn: Schöningh, 1998: 32. ISBN 978-3506758057.

Olbrich E, Otterstedt C. Menschen brauchen Tiere. Grundlagen und Praxis der tiergestützten Pädagogik und Therapie. Stuttgart: Franckh-Kosmos, 2003: 17. ISBN 9783440094747.

Olbrich E, Jonas I. Ein Plädoyer für die Tierhaltung in Altenund Pflegeheimen. Köln: Kuratorium Deutsche Altershilfe, 2008.

Otterstedt C, Rosenberger M. Gefährten - Konkurrenten Verwandte: Die Mensch-Tier-Beziehung im wissenschaftlichen Diskurs. Göttingen: Vandenhoeck und Ruprecht, 2009: 184. ISBN 978-3525404225.

Pepels W. Marktforschung. Verfahren, Datenauswertung, Ergebnisdarstellung. Düsseldorf: Symposion Publishing, 2008: 357. ISBN 978-3939707233.

Perkins J, Bartlett H, Travers C, Rand J. Dog-assisted therapy for older people with dementia: a review. Australas J Ageing. 2008 Dec;27(4):177-82.

Raina P, Waltner-Toews D, Bonnett B, Woodward C, Abernathy $\mathrm{T}$. Influence of companion animals on the physical and psychological health of older people: an analysis of a one-year longitudinal study. J Am Geriatr Soc. 1999 Mar;47(3):323-9.

Rheinz H. Eine tierische Liebe. München: Kösel, 1994: 18. ISBN 978-3466343065.

Scheibeck R, Stellwag C, Pallauf M, Seeberger B. Dogs and the Elderly: a Research Study from a Gerontological Perspective. Gerontologica. 2011 Jun; 1(1):105-20.

Serpell J. Das Tier und wir. Eine Beziehungsstudie. Zürich: Müller Rüschlikon, 1990. ISBN 978-3275009800.

Strübing J. Grounded Theory: Zur sozialtheoretischen und epistemologischen Fundierung des Verfahrens der empirisch begründeten Theoriebildung. Wiesbaden: VS, 2008. ISBN 978-3531158327.

Thorpe RJ Jr, Kreisle RA, Glickman LT, Simonsick EM, Newman AB, Kritchevsky S. Physical activity and pet ownership in year 3 of the Health ABC study. J Aging Phys Act. 2006 Apr;14(2):154-68.

Tribet J, Boucharlat M, Myslinski M. Animal-assisted therapy for people suffering from severe dementia. Encephale. 2008 Apr;34(2):183-6. Epub 2007 Sep 11.

Univie. Ethnographie als Prozess der Datenerhebung. Retrieved August 4, 2010 from

http://www.univie.ac.at/ksa/elearning/cp/qualitative/ qualitative-51.html.

Virués-Ortega J, Buela-Casal G. Psychophysiological effects of human-animal interaction: theoretical issues and longterm interaction effects. J Nerv Ment Dis. 2006 Jan; 194(1):52-7.

Wells DL. Associations between pet ownership and self-reported health status in people suffering from chronic fatigue syndrome. J Altern Complement Med. 2009 Apr; 15(4):407-13.

Yabroff KR, Troiano RP, Berrigan D. Walking the dog: is pet ownership associated with physical activity in California? J Phys Act Health. 2008 Mar;5(2):216-28.

Received: June 29, 2011 / Accepted: July 14, 2011

Address for correspondence:

Roswitha Scheibeck

Marktstraße 21

$6230 \mathrm{Brixlegg} /$ Tirol

Austria

E-mail: roswitha.scheibeck@umit.at martin.pallauf@umit.at 